\title{
Pedagogias culturais e proposições pedagógicas: experimentações artísticas com crianças
}

\author{
Culture pedagogies and pedagogical propositions: \\ Artistic experiences for children
}

\section{Pedagogías culturales y propuestas pedagógicas: experimentaciones artísticas con la niñez}

\author{
Jéssica Maria Freisleben ${ }^{1}$ \\ iD https://orcid.org/0000-0003-3581-3979 \\ Lutiere Dalla Valle ${ }^{2}$ \\ iD https://orcid.org/0000-0002-8547-7793 \\ Márcia Silveira Cassol ${ }^{3}$ \\ iD https://orcid.org/0000-0003-2763-2502
}

Resumo: Este artigo tem por objetivo analisar experimentações artísticas com crianças a partir de quatro proposições desenvolvidas em distintos espaços educativos na cidade de Santa Maria - RS. As perspectivas educativas da cultura visual, respaldada por Raimundo Martins (2011), emaranhada pelas reflexões de Susana Rangel Vieira da Cunha (2010, 2014, 2017), e da bricolagem (KINCHELOE; BERRY, 2007) compõem o campo teórico-metodológico que busca problematizar produções gráficas infantis

\footnotetext{
${ }^{1}$ Mestra em Educação pela Universidade Federal de Santa Maria, Brasil. Professora de Arte no Colégio Nossa Senhora de Fátima. E-mail: jessicafreisleben@hotmail.com

2 Doutor em Artes Visuais e Educação pela Universitat de Barcelona, Espanha. Professor Associado na Universidade Federal de Santa Maria. Atua na formação de Professores (Cursos de Pedagogia e Artes Visuais).E-mail: lutiere@dallavalle.net.br

${ }^{3}$ Especialista em Tecnologias na Educação pela PUC/RIO (2010). Atua como professora titular da Prefeitura Municipal de Santa Maria e junto a Secretaria de Educação do Estado do Rio Grande do Sul. E-mail: marciasilcass@gmail.com
} 
entrelaçadas por seus repertórios visuais. Dessa maneira, a escrita aborda modos de propor e refletir a experiência do fazer artístico com crianças, estimulando seu protagonismo a partir da potência pedagógica das narrativas visuais que habitam seus imaginários. Os resultados apresentados enredados pelo referencial teórico oferecem pistas para seguirmos investigando e propondo o campo das pedagogias culturais como alternativa às práticas pedagógicas.

Palavras-chave: Pedagogias Culturais. Proposições Pedagógicas. Experimentações Artísticas.

Abstract: This article aims to analyze artistic experiments with children from four propositions developed in different educational spaces in the city of Santa Maria - RS. The educational perspective of visual culture by Raimundo Martins and Irene Tourinho (2011) intertwined with the reflections of Susana Rangel Vieira da Cunha $(2010,2014,2017)$ and Bricolage (KINCHELOE, J; BERRY, K, 2007) construct the theoretical-methodological field that seeks to problematize children's artistic productions concerning their visual repertoires. In this way, the present study approaches ways of proposing and reflecting on the experience of art-making with children, stimulating their protagonism based on the pedagogical power of the visual narratives from their imaginations. The results presented, entangled by the theoretical framework, offer clues to continue investigating and proposing the field of cultural pedagogies as an alternative to pedagogical practices.

Keywords: Culture Pedagogies. Pedagogical Propositions. Artistic Experiments.

Resumen: Este artículo tiene como objetivo analizar experimentaciones artísticas con niños a partir de cuatro propuestas desarrolladas en diferentes espacios educativos de la ciudad de Santa María - RS. La perspectiva educativa de la Cultura Visual apoyada por Raimundo Martins e Irene Tourinho (2011) enmarañada por las reflexiones de Susana Rangel Vieira da Cunha $(2010,2014,2017)$ y del bricolaje (KINCHELOE, J; BERRY, K, 2007) forman el campo teórico-metodológico que busca problematizar las producciones gráficas de los niños entrelazadas por sus repertorios visuales. De esta manera, el texto aborda formas de proponer y reflexionar sobre la experiencia de hacer arte con los niños, estimulando su protagonismo a partir de la potencia pedagógica de las narrativas visuales que habitan su imaginación. Los resultados presentados entrelazados por el marco teórico ofrecen pistas para seguir investigando y proponiendo el campo de las pedagogías culturales como alternativa a las prácticas pedagógicas.

Palabras-clave: Pedagogías Culturales. Prácticas Pedagógicas. Experiencia Artística.

\section{Apontamentos iniciais}

Por que os peixes dentro d'água são mais ágeis que os pássaros no céu quando deveria ser o contrário, já que a água é mais pesada e densa do que o ar?

(ISAACSON, 2017, p. 23)

A pergunta que abre esta escrita teria sido feita há meio século pelo jovem florentino Leonardo Da Vinci, conforme relata Walter Isaacson (2017). Mas poderia ser uma pergunta atual, proferida por uma criança ao observar o mundo à sua volta durante seus processos de descobrimento e apreensão simbólica dentro da cultura da qual participa. Sabemos que é na infância que surgem os infinitos porquês, atravessados por instâncias 
próprias dessa faixa etária: uma possível ingenuidade diante da complexidade do mundo, que se apresenta baseada na simplicidade das coisas, sobretudo a partir da observação.

Em seu livro, Walter Isaacson (2017) nos convida a esmiuçar a vida e a obra de Da Vinci a fim de subverter a perspectiva de uma genialidade quase divina concedida ao artista, a partir de uma abordagem que prima pela curiosidade. Desde a mais tenra idade, Leonardo teria desenvolvido seu próprio processo de descoberta com base na observação atenta e, ao mesmo tempo, pela capacidade inventiva da fantasia, sobretudo pelo movimento contínuo de fazer perguntas, querendo saber sobre a "cor do céu" ou "como funcionava a língua do pica-pau" (ISAACSON, 2017, p. 556). Talvez, pelo fato de lhe ter sido negado o acesso à escola tradicional, havia uma curiosidade incessante que lhe permitiu inventar teorias e métodos para explicar aquilo que chamava sua atenção. Sobretudo, a partir de um olhar transdisciplinar (ou da não disciplina), isto é, destituído de estruturas hierárquicas e conceitos já assentados, por enfoques mais conectivos, plurais e diversificados. Para ele, o interessante estaria justamente na prática de estabelecer relações, nas junções entre os distintos campos, assim como fazem as crianças quando experimentam, juntam, sobrepõem e inventam mundos possíveis e pequenas engenhocas animadas que atestam o potencial de sua criatividade.

Imbuída dessas reflexões iniciais, esta escrita também traz perguntas e suposições inventadas por crianças do nosso tempo, a fim de ativar algumas pistas para seguirmos pensando e propondo práticas educativas em artes visuais. Baseadas em suas percepções de mundo, em seus modos de ver, compreender, simbolizar e representar por meio do fazer artístico, essas infâncias complexas (e diversificadas) têm muito a contribuir com nossas práticas pedagógicas, principalmente no que tange aos artefatos culturais/visuais que consomem e habitam seus imaginários coletivos e individuais (CUNHA, 2017). Durante nossas andanças por diferentes tempos e espaços educativos, como docentes e pesquisadores, temos nos deparado com inúmeras potências ao tomar como dispositivos pedagógicos as referências visuais que adornam mochilas, cadernos e demais objetos escolares de uso individual e coletivo. Sabemos que há inúmeras maneiras de estimular processos cognitivos e criativos, assim como inúmeras práticas e experimentações artísticas com crianças no ambiente escolar. 
Entretanto, neste contexto de escrita, nossa atenção está voltada às referências visuais que as crianças trazem para a sala de aula como potência pedagógica para o ensino das artes visuais.

Como questão problema, nos propomos examinar como ocorreram algumas experimentações artísticas em diferentes espaços escolares e sua relação com o protagonismo infantil alimentado pelo exercício crítico a partir de referências visuais coletadas ao longo de suas trajetórias cotidianas. Desse modo, serão articuladas imagens enquanto dispositivos pedagógicos (VALLE, 2020) que favorecem o desenvolvimento de práticas educativas entrelaçadas não apenas no campo das artes visuais, mas também imagens dos anúncios publicitários, imagens retiradas da internet; sobretudo, imagens presentes nos materiais e acessórios escolares.

Dentro da sala de aula, é possível encontrar repertórios visuais variados. Ao observarmos as brincadeiras, podemos identificar referências e escolhas que participam ativamente na construção das identidades e no modo como as crianças se relacionam entre si. Capturadas pela lógica de consumo, as crianças também tendem a reproduzir situações de atração e repulsa em relação aos objetos ou a referências visuais que "invadiram nossas vidas criando outros modos e outras perspectivas para ver" e se relacionar (COSTA, 2012, p. 264).

Neste ínterim, a perspectiva educativa da cultura visual tem possibilitado abordagens que levam em consideração referências imagéticas - na maioria das vezes criadas pelas produções cinematográficas - que envolvem objetos destinados ao consumo infantil. Portanto, ao nos posicionarmos a partir deste enfoque, estamos lidando com a percepção visual do sujeito, assim como com as narrativas que ele produz ao estabelecer relações com suas próprias visões de mundo. Além disso, tem nos permitido abandonar ideias prescritivas da apreciação estética e contribuído para problematizar o entendimento não apenas do campo artístico, mas também (e sobretudo) das relações com as múltiplas temporalidades das imagens. (MARTINS; TOURINHO, 2011).

Assim, para enredar o texto, articulamos quatro experiências disparadoras que acreditamos que possam contribuir com a temática enunciada: a) convidando princesas para uma conversa; b) perguntando aos super-heróis; c) olhando para a cidade; e d) reconfigurando medos. Ao pontuarmos alguns campos conceituais com os quais operamos, os relatos 
entrelaçados às percepções e diálogos intentam estabelecer relações entre o que consideramos pedagogias culturais e proposições pedagógicas vinculadas ao campo das artes visuais.

\section{A Perspectiva Educativa da Cultura Visual como ponto de partida}

Esta abordagem tem nos oferecido importantes contribuições para pensar e articular proposições pedagógicas nos variados contextos de atuação docente. Sem a pretensão de nos brindar com um método ou receituário - muito pelo contrário -, os estudos da cultura visual nos têm possibilitado estabelecer relações com outros campos do conhecimento, sobretudo com a filosofia, a sociologia, a psicologia, os estudos culturais, os estudos sobre cinema, os estudos queer, as perspectivas feministas, entre outras, justamente por se tratar de um campo híbrido que se nutre de outras disciplinas (HERNÁNDEZ, 2007). Para Kevin Tavin (2009, p. 226), "enquanto área de estudo, a cultura visual busca analisar e interpretar a riqueza de experiências visuais (multimediadas) em uma dada cultura, bem como suas práticas visuais: as interações entre os observadores e aquilo que é observado".

Para o autor, a cultura visual busca romper com as hierarquias impostas pela hegemonia branca, eurocêntrica e patriarcal destinada aos estudos das imagens, os quais, historicamente, seguem exercendo forte influência sobre nossas formas de ver e de sermos vistos. Além desses aspectos, esse enfoque para as Artes e para a Educação abre múltiplas vias de acesso à produção do conhecimento: caminhos relacionais, conectivos e experimentais, em que a interpretação e a singularidade do sujeito que olha e que é visto, enredado pelas tramas sociais e culturais, tornam-se elementos centrais para a produção de sentido.

Se tomarmos, como referência, nossas experiências cotidianas com as imagens produzidas por distintas "temporalidades" (MARTINS; TOURINHO, 2011) e que se proliferam em velocidade exacerbada através das redes sociais, podemos rapidamente concluir sobre a necessidade (e a urgência) de essas novas formas de representação visual (especificamente as digitais) fazerem parte de nossos planos de aula, assim como outros processos que envolvem práticas pedagógicas na contemporaneidade. Estamos de acordo com Paul Duncum (2011) quando ele argumenta que:

Olhar de professor, Ponta Grossa, v. 24, p. 1-32, e-117634.077, 2021. 
A arte-educação precisa mudar para que possa abordar os efeitos sociais da proliferação sem precedentes da imagética comercial que, atualmente, satura a vida diária em várias partes do mundo. O modo como vivemos hoje - como vivem, em especial, nossos alunos eletronicamente conectados - é muito diferente do mundo retratado pela prática educacional artística convencional, que continua a enfocar elementos e princípios modernistas, bem como meios de comunicação tradicionais (DUNCUM, 2011, p. 15).

Assim sendo, partindo dos referenciais visuais midiáticos das crianças, podemos nos situar sobre suas escolhas, seus modos de ser e agir nas brincadeiras, assim como suas produções visuais, uma vez que tendem a reproduzir grande parte das experiências estéticas (frente à TV ou a demais dispositivos móveis de reprodução de imagens) quando solicitadas a criar narrativas (sejam elas visuais ou verbais). É recorrente a citação de personagens oriundos de filmes populares nos desenhos feitos por crianças nos espaços educativos em que temos transitado. Sem a pretensão de generalizar tal percepção, observamos que, independentemente, do poder aquisitivo ou do acesso a bens de consumo (sobretudo dispositivos eletrônicos), é significativa a presença de códigos visuais produzidos pelo cinema. Giroux (2003) aponta que isso se dá tanto nas referências às brincadeiras (como, por exemplo, super-heróis da Marvel e princesas da Disney) quanto em nas narrativas das crianças, exercendo forte influência em seus imaginários, muito além do "entretenimento". Para o autor:

A força e o poder da indústria cinematográfica é evidente na intensa influência que exerce sobre a imaginação popular e consciência pública. A diferença dos bens de consumo e seu uso, os filmes produzem imagens, ideias, ideologias que conformam tanto as identidades individuais como as nacionais. $O$ poder de seu alcance e a extensão de sua comercialização reflete como se utilizam das referências cinematográficas para vender camisetas, copos, posters, adesivos e todo um abanico de produtos kitsh (GIROUX, 2003, p. 19).

Dessa forma, considerando a potência pedagógica desses artefatos visuais, à luz das pedagogias culturais, podemos estabelecer pontos de conexão entre Arte, Cultura Visual e Educação, uma vez que estão atreladas experiências estéticas que seguem contribuindo para a configuração dos imaginários infantis (CUNHA, 2010).

Ao tomar o campo das pedagogias culturais como perspectiva de trabalho dentro da sala de aula, estamos de acordo com Fernando Miranda (2014, p. 311) quando ele afirma que, "para reflexionarmos sobre a pedagogia das imagens, devemos tomar muito seriamente os 
repertórios visuais, tanto no que mostram e no que ocultam, como nas maneiras em que são expostos ou distribuídos material ou discursivamente". Ou seja, centramos nossa atenção justamente nas conexões que as crianças estabelecem ao narrar a vida cotidiana através de suas produções simbólicas quando desafiadas à experiência artística.

Fernando Miranda também adverte sobre a necessidade de entendermos, a partir do cotidiano espetacular, a "função pedagógica das imagens", a qual é potencialmente enredada pelos meios massivos e pelos "espaços transitáveis" em que nos situamos enquanto sociedade (MIRANDA, 2014, p. 312). Sobretudo no que diz respeito aos contextos educativos formais de ensino, nos quais convivem variadas narrativas trazidas pelos sujeitos, que, fora dos muros da escola, vivenciam outras experiências pedagógicas ao serem interpelados pelas imagens midiáticas (MOMO, 2014).

Consideramos essas produções que invadem - ou que são convidadas pelas crianças a compor os espaços escolares - como pontos de partida para discussões, reflexões, ampliação de repertórios, experimentações artísticas e desconstrução de possíveis versões estereotipadas, contribuindo para outras formas de ler e ver, conscientes e reflexivas, diante de tantas imagens que são, na maioria das vezes, consumidas passivamente (CUNHA, 2014b). Kevin Tavin e David Anderson (2010, p. 59) afirmam que "a Disney fornece locais poderosos para a pedagogia cultural, nos quais aprendemos sobre o mundo e sobre nossas relações", o que nos exige, enquanto docentes, abertura às suas potências enquanto disparadores às aprendizagens.

Nesse sentido, entendemos que o conhecimento sobre si e sobre o mundo não se limita ao que está dentro do espaço escolar, haja vista que "a forma envolvente pela qual a pedagogia cultural está presente na vida de crianças e jovens não pode ser simplesmente ignorada por qualquer teoria contemporânea do currículo" (SILVA, 1999, p. 140). Assim, a perspectiva educativa da cultura visual enfatiza a importância da compreensão crítica das imagens, considerando as interpretações subjetivas mobilizadas pela experiência estética (MARTINS; TOURINHO, 2011). Isso significa compreender que obras de arte, assim como imagens midiáticas, cinematográficas, da internet, entre outras, não correspondem a produções simbólicas neutras, ou seja: estão atreladas a comunidades discursivas de quem as produziu 
intencionalmente (ideológica, cultural, histórica e socialmente articuladas). Como argumentam Raimundo Martins e Irene Tourinho:

O propósito da educação da cultura visual não é substituir conceitos, abordagens curriculares ou práticas de ensino da arte, mas introduzir e incorporar no fazer artístico a discussão do lugar/espaços das imagens qualquer imagem ou artefato artístico - e seu potencial educativo na experiência humana (MARTINS; TOURINHO, 2011, p. 57).

Ao estabelecer espaços de escuta atenta às relações afetivas que as crianças estabelecem com personagens e narrativas visuais que adornam seus objetos cotidianos, podemos lançar perguntas para problematizar de que modo determinadas representações visuais materializam modos de ser menino ou menina, como são seus gestos e atitudes, ampliando seus repertórios ao apresentar-Ihes, talvez, outras narrativas que rompem com estas mesmas lógicas apresentadas. Meninos que usam rosa, meninas valentes, brincadeiras destituídas de relações hierárquicas de gênero poderão ser potencializadas quando forem movimentadas perguntas em relação às estórias apresentadas.

Ao compreender o território infantil a partir de suas falas, pensamentos, ações e representações simbólicas, talvez possamos propor experimentações artísticas que possam abarcar não apenas o campo artístico institucionalizado (aquela perspectiva histórica linear das artes visuais), mas também abordagens mais amplas, na medida em que tencionamos conceitos de representação. Isto é, ao aproximarmos a experiência estética dos objetos à vida cotidiana, estaremos propondo que as manifestações artísticas (enquanto expressões humanas) ultrapassam versões institucionalizadas e hierárquicas das Artes: nos interpelam e surgem dos variados contextos e materialidades.

\section{Pedagogias Culturais e a potência pedagógica das imagens}

Neste contexto, a noção de pedagogias culturais vincula-se à perspectiva educativa da cultura visual, cujo foco reside em "indagar sobre as maneiras culturais de olhar e seus efeitos sobre cada um de nós" (HERNÁNDEZ, 2010, p. 71). Ao expandir a potência pedagógica dos objetos e artefatos visuais produzidos pela indústria do entretenimento, por exemplo, estamos considerando o terreno pedagógico desses objetos como prática de "produção de 
identidades" e, sobretudo, vinculando o caráter afetivo e de alto impacto à construção de imaginários coletivos.

As dimensões culturais e políticas dos artefatos visuais com os quais as crianças convivem diariamente não podem ser deixadas de lado quando pensamos em processo educativo. Diante das imagens que formam seus repertórios e imaginários coletivos, sobretudo a partir dos produtos destinados ao consumo, podemos propor experiências artísticas que, por meio de perguntas e problematizações, podemos examinar discursos, refletir e subverter possíveis efeitos de dominação cultural.

No texto "Pedagogias Culturais: o processo de (se) construir em um campo que vincula conhecimento, indagação e ativismo", escrito por Fernando Hernández, e que integra o livro "Pedagogias Culturais", organizado por Raimundo Martins e Irene Tourinho (2014), o autor propõe situar o campo como um "guarda-chuva das pedagogias culturais" envolvendo campos conceituais baseados em "conhecimento", "intervenção" e "ativismo", caracterizado por alguns aspectos, dentre os quais destacamos:

Desvelar, questionar e subverter discursos que naturalizam o olhar ao redor de imagens e de relações que, como visualizadores ou produtores, mantemos com elas; propiciar modos de indagação, desvelamento e ação frente às estruturas - discursos - que nos constituem e nos naturalizam; projetar modos de narrar - de dar conta - que além de incluir os participantes, contribuam para expandir outros sentidos de compreensão e experiências de relação (HERNÁNDEZ, 2014, p. 348).

Diante disso, partimos do pressuposto de que experiências sensíveis e de aproximação com imagens se tornam significativas quando acionadas pelas relações afetivas - as quais, normalmente, são ativadas pelas crianças quando elas se referem ao universo da fantasia e da ficção. Assim, entendemos que imagens midiáticas se constituem como disparadoras de produção de conhecimento, sobretudo de indagações. Ao confrontar as estruturas visuais que constituem determinadas narrativas, podem ser operacionalizadas novas percepções, e, consequentemente, a ampliação de olhares e repertórios visuais no que diz respeito ao que selecionam e movimentam em suas falas e produções artísticas.

Ao serem desafiadas a falar sobre suas escolhas relativas a personagens que afetivamente têm habitado seus materiais escolares, assessórios ou adereços, podem ser 
acionados vínculos de conexão entre a experiência singular e os novos repertórios propostos pelo(a) professor(a). A partir daí, experiências artísticas baseadas na experimentação de materiais (gráficos, pictóricos, plásticos, sonoros, etc.) ganham potência ao estabelecerem conexões entre imagens prévias e novas elaborações visuais. Como afirma Cunha (2014a):

É na interação da criança com os objetos de conhecimento (desenho, pintura, modelagem, etc.) que o processo expressivo se constitui. Para que esse processo expressivo seja desencadeado, para que tenha significado para as crianças e para que possibilite leituras e expressões plurais sobre o mundo são necessárias intervenções pedagógicas desafiadoras (CUNHA, 2014a, p. 16).

Ou seja, é necessário desafiar as crianças partindo da problematização das imagens que compartilham, das ideias que as imagens disparam ao serem ativadas nas conversas coletivas em sala de aula, situando-as nas comunidades de discurso em que se inserem, pois, "a contextualização tem a ver com as práticas críticas sobre as maneiras, mediante as quais o que vemos nos conforma, nos faz ser o que outros querem que sejamos" (HERNÁNDEZ, 2010, p. 77).Assim, partir do repertório cultural e imagético já conhecido das crianças nos ajuda a estabelecer relações com obras de artistas de diferentes períodos da História da Arte, como obras de Arte Contemporânea, Arte Urbana e Patrimônio Cultural, expandindo o escopo de possibilidades inventivas e criativas relacionadas ao campo das visualidades. Da mesma maneira, estimula a prática de estabelecer relações entre as distintas imagens com as quais interagem:

É fundamental desvelar o repertório de imagens objetivas e subjetivas, o mundo real e o da fantasia que cada criança traz de seus contextos socioculturais, pois, a partir das imagens particulares, o seu repertório das imagens e objetos também implica disponibilizar às crianças elementos produzidos em outros contextos e épocas como as imagens da história da arte fotografias e vídeos, objetos artesanais produzidos por culturas diversas, brinquedos, adereços, vestimentas, utensílios domésticos, etc. (CUNHA, 2014a, p. 22).

Quando falamos em repertórios visuais, estamos nos referindo àquelas imagens que participam das escolhas individuais: imagens que as crianças selecionam, guardam na memória e que voltam a fazer parte de suas manifestações, seja nas narrativas inventadas, seja nas brincadeiras compartilhadas nos espaços coletivos. Na cultura contemporânea, por meio dos 
dispositivos móveis, é comum produzir muitas imagens, compartilhá-las, consumi-las sobretudo como entretenimento. Entretanto, cabe refletir e problematizar quais imagens merecem atenção, bem como quais podem ser descartadas ou não despertam o interesse. Ou seja: como se dá esse processo de seleção daquilo que vemos?

Neste ínterim, acreditamos que é primordial indagar sobre o mundo das imagens, cujo acesso diário e frenético faz parte da vida contemporânea de grande parte dos sujeitos em idade escolar. Em ambientes educativos formais, problematizações em torno do que mostram e do que ocultam as grandes narrativas hegemônicas potencializam outras interpretações, assim como o desenvolvimento crítico dos estudantes. O que está fora da escola também participa dos processos educativos; pois, conforme apontado por Silva (1999), "as outras instâncias culturais também são pedagógicas, também têm uma 'pedagogia', também ensinam alguma coisa" (SILVA, 1999, p. 139). É a partir das crianças que esse fora tem entrado na escola e participado ativamente de suas elaborações visuais, quer queiramos ou não. Assim, acreditamos que aquilo que as crianças conhecem e observam em casa na televisão, no telefone celular, no caminho de casa até a escola e seus arredores, como anúncios publicitários, e em tantos outros lugares, podem disparar experimentações artísticas significativas, além de incentivar o protagonismo e o posicionamento crítico acerca de suas escolhas.

Nesse sentido, entendemos que tomar a sedução exercida pelas pedagogias culturais como disparador não quer dizer reduzir a relevância de determinados conteúdos formais, menos ainda anular escolhas e planejamentos do(a) professor(a). Significa incluir outras perspectivas, sobretudo valorizar os conhecimentos das crianças sobre o mundo fora da escola, partir de suas escolhas, curiosidades e do que entendem sobre as narrativas visuais que selecionam e que as acompanham materializadas em objetos. Algo que, de acordo com Nunes (2014, p. 35), "não significa 'pedagogizar' as imagens ou artefatos culturais, transformando-os em conteúdos, mas trazer para as salas de aula as discussões, as problemáticas e os conflitos mediados por esses elementos culturais".

Ampliar os repertórios nos convida a estarmos em constante espreita ao que nos acontece, às experiências visuais que atravessamos diariamente e que nos afetam. Quanto maior nosso repertório, mais amplas e plurais poderão ser nossas abordagens educativas 
(VALLE, 2020). Obviamente, quanto maior o número (e variedade) de artistas e produções artísticas com que tivermos contato ou conhecimento, maiores, mais amplas e mais abrangentes poderão ser nossas proposições pedagógicas. A escolha de um repertório para um encontro educativo nunca é neutra: estamos sempre implicados com nossa posição (queiramos ou não).

\section{Disparadores: entre perguntas e afetos, muitos projetos!}

Entre tantas experiências que temos vivenciado ao longo dos últimos cinco anos vinculados a um grupo de pesquisa de que participamos, selecionamos quatro experimentações desenvolvidas em momentos e contextos distintos. Tais experimentações foram selecionadas para delinear a interlocução entre abordagens teórico-metodológicas citadas anteriormente, assim como para apontar algumas pistas para seguirmos pensando sobre o campo das pedagogias culturais como dispositivos para o fazer artístico com crianças.

Para esta escrita, recorremos também à perspectiva da bricolagem, a qual tem o caráter processual como fator preponderante dentro da experiência artística. Esta é uma abordagem "que envolve construção, reconstrução, diagnóstico conceitual, negociação e readaptação" (KINCHELOE; BERRY, 2007, p. 17). Quando as crianças são desafiadas a ressignificar referências imagéticas esmiuçando o que encontram em seus repertórios, o diálogo se desloca pela lógica da conexão aberta ao improviso, o que pode acontecer quando operamos com "dispositivos pedagógicos" (VALLE, 2014, p. 150). Estes últimos são entendidos como elementos que podem ser constituídos por imagens, artefatos visuais, objetos que disparam experiências pedagógicas, etc., ou seja, são dispositivos que movimentam processos cognitivos conectivos ao fomentarem a prática de estabelecer relações (VALLE, 2020).

Entre tantos percursos e recursos dos quais podemos fazer uso, quando adotamos a bricolagem como perspectiva metodológica trouxemos os seguintes aspectos: a) a observação-participante, com problematizações formuladas junto às crianças a partir de suas percepções sobre as dinâmicas propostas; b) experimentações artísticas articuladas às indagações; e c) o uso de diários visuais como registro das ações desenvolvidas, constituído 
por anotações e fragmentos de diálogos capturados durante as intervenções realizadas em espaços escolares.

Ao destacar a pertinência de pensarmos as crianças como atores sociais e, da mesma forma, a importância do fomento a espaços onde elas possam apresentar suas produções visuais, ressaltamos que a pesquisa - assim como práticas educativas com crianças - não segue um roteiro rígido nem tem um manual a ser seguido, sobretudo quando se propõe uma criação coletiva que tem a prática artística como mote central. Igualmente, a dimensão ética no uso de dados que possam comprometer as integridades das crianças deve ser rigorosamente levada em consideração. Neste ínterim, enfatizamos que, durante todas as proposições citadas ao longo do texto, perpassam o sentimento de respeito às suas singularidades quando tratamos de pesquisas com crianças. Em todas as ocasiões, contamos com consentimento de todas as pessoas envolvidas, principalmente das crianças: sempre convidadas a participar das proposições e se manifestarem sobre seus desejos e anseios.

Logo, escolher o referencial teórico-metodológico que compreende as crianças como sujeitos produtores de cultura é essencial, bem como atentar aos cuidados éticos e metodológicos para realizar quaisquer que sejam as práticas pedagógicas. Isso porque, "na investigação com crianças, são as crianças que detêm o saber, dão a permissão e fixam as regras para os adultos" (GRAUE; WALSH, 2003, p. 77). Sendo assim, sempre que necessário, reiterávamos essa condição, solicitando permissão e consentimento para adentrar e partilhar com elas esses espaços e aprendizagens.

A partir de diferentes contextos escolares situados na cidade de Santa Maria (RS), as práticas artísticas que enredam esta escrita foram desenvolvidas entre os anos de 2018 e 2019, perpassando duas escolas da rede municipal de ensino e uma instituição de educação básica (cuja mantenedora é uma rede privada de ensino) localizada em uma zona periférica da cidade, caracterizada por atender crianças em situação de vulnerabilidade social. Nesta conjuntura, uma escola municipal corresponde ao local de trabalho de uma das pesquisadoras e a outra recebe o projeto de voluntariado, em que uma das pesquisadoras realizou ações de voluntariado. A instituição vinculada ao projeto social de atendimento à comunidade periférica 
consistiu em uma atuação voluntariada atrelada a uma pesquisa de mestrado, vivências atravessadas pelo compartilhamento coletivo no grupo de pesquisa que integramos.

\section{Convidando princesas para uma conversa}

- Tenho uma dúvida, meninos não brincam com bonecas? (pesquisadora)

- Então profe, pode brincar, mas a gente não gosta muito. (menino A)

- Eu acho que menino não pode brincar com boneca. (menino B)

- Pode sim profe, mas eles nunca brincam com a gente. (menina G)

- Meu pai não gosta muito, mas eu não vejo problema nisso. (menino M)

- E tu imagina porque teu pai não gosta que tu brinque com bonecas? (pesquisadora)

- Profe, ele me disse que isso é coisa de menina, que brincar de boneca é igual cuidar de bebê, coisa de mulher. (menino M)

- Mas e o teu pai não cuidou de tí? Não cuida dos filhos? Pois, assim como a mãe o pai também é responsável por cuidar dos filhos, não concorda? (pesquisadora)

- Sim profe, eu entendo, a outra profe também já falou isso, mas acho que meu pai não entende. (menino $M$ )

- É sim, a outra profe disse que podemos brincar com "coisas de menina" e usar rosa também, a gente já sabe. (menino $R$ )

- Mas eles não tem paciência pra cuidar da boneca e cuidar da casa, aí a gente diz pra eles trabalharem fora de casa. (menina D)

(Conversas entre crianças. Registros dos autores, 2018)

O relato que abre esta subseção resulta de diálogos desenvolvidos junto a uma turma de primeiro ano do ensino fundamental, no ano de 2018, na unidade social citada anteriormente. As problemáticas disparadas com o grupo perpassavam questões de gênero relacionadas ao uso das cores azul e rosa e configuraram algumas fagulhas para o trabalho a ser proposto. Tanto as brincadeiras como os discursos estavam demarcados pelas relações masculino/feminino e sob a perspectiva de concepções estereotipadas, machistas ou misóginas, implícitas ou explícitas quando relatavam situações cotidianas. Muitas vezes, relatos de situações familiares que vinham à tona conforme avançávamos nas discussões.

Tomando por base algumas convenções sociais e culturais, emergiram noções de ser menino ou menina a partir das cores, brincadeiras e referências visuais de consumo a partir das narrativas produzidas pela cinematografia dominante (naquele momento, fazendo referência a Barbie, princesas da Disney e super-heróis da Marvel). Tomadas por essas provocações, muitas crianças argumentavam serem favoráveis a romper com perspectivas 
binárias; porém, minutos depois, faziam referência às perspectivas familiares, crenças e valores que vinculavam noções de masculinidade e feminilidade ainda demarcadas pelo preconceito. Ao serem questionadas sobre suas percepções acerca dos brinquedos e objetos, surgia a discussão:

- Eu acho que menina pode jogar e brincar com o que quiser. (menino M)

- Menina pode até jogar com videogame. (menino L)

- Mas vocês não deixam a gente brinca com vocês, às vezes. (menina J)

- É que às vezes, as brincadeiras podem machucar vocês, por isso a gente não deixa. (menino M)

(Conversas entre crianças. Registros dos autores, 2018)

As crianças apresentavam seus entendimentos sobre brinquedos e brincadeiras e mencionavam que poderiam ser acessíveis a todos(as), independente do gênero; no entanto, em seguida, disputavam, frente às questões naturalizadas das práticas socioculturais, o acesso a brinquedos designados aos seus gêneros correspondentes. Ao mesmo tempo em que as meninas afirmavam que poderiam se envolver com jogos esportivos, os meninos manifestavam preocupação, por acreditarem em suas fragilidades e aspectos de delicadeza que thes eram atribuídos.

Ao explorar o comentário de uma das meninas - "a gente prefere brincar de princesa, de Barbie, os meninos gostam de lutinhas e corrida" -, percebemos o quanto precisávamos fomentar práticas que pudessem desnaturalizar dicotomias, sobretudo no que diz respeito às posições que mulheres e homens podem ocupar, assim como meninas e meninos, livres de concepções fechadas e limitadoras. Na turma em questão, o assunto divergiu opiniões, pois os meninos admitiam que qualquer brincadeira ou brinquedo poderia ser desfrutado tanto por meninos como pelas meninas, mas foram extremamente resistentes no momento de brincar com os brinquedos das meninas.

A partir dos diálogos com as crianças e da observação das brincadeiras, percebemos que as crianças não apenas reproduziam as culturas adultas, como produziam, a partir delas, as suas culturas infantis, supondo situações reais atravessadas pelo faz-de-conta, na quais seguiam corporificando formas de ser e existir baseadas em modelos capturados ao longo de suas experiências cotidianas. Neste contexto, nos deparamos com o tema da cor rosa como 
uma das questões que ainda apontava versões estereotipadas em relação ao uso das cores. Diante do cenário apresentado dentro da sala de aula, mencionamos não ter visto nenhuma mochila ou caderno com predomínio da cor rosa pertencente a um menino. Questionadas, as crianças responderam que, normalmente, não encontravam, nas lojas, utensílios para os meninos com essa cor, o que, segundo elas, não seria problema se um menino utilizasse algum acessório rosa. Entretanto, admitiam que, caso isso acontecesse, poderia causar estranheza.

Nos encontros que se seguiram, a problemática foi se estruturando e, em determinado momento, solicitamos que apresentassem seus cadernos, estojos, mochilas, lápis, dentre outros materiais escolares. Para nossa surpresa, a figura da princesa se destacou em relação a todas as demais referências. As meninas enfatizaram que as princesas não usavam calças, que tinham como características fazer o bem às pessoas, sempre dispostas a ajudar os necessitados e, em sua maioria, eram loiras e magras. Por meio de diferentes pedagogias culturais, elas já haviam apreendido que, para ser princesa, existiam padrões específicos, assim como padrões de conduta preestabelecidos. As referências das princesas, em sua maioria, originaram-se nos desenhos animados infantis, assim como relativos à boneca Barbie, em que o referencial de princesa se constitui partir dos cabelos loiros e lisos e dos olhos azuis, legitimando um padrão de beleza específico, como já mencionado.

Logo, como ponto inicial da experimentação, organizamos coletivamente uma lista de características das princesas (algumas supracitadas) e, coletivamente, começamos a indagálas, apontando no quadro palavras-chave verbalizadas pelas crianças. A experimentação artística que propusemos foi a criação de uma personagem que seria a materialização de uma princesa na concepção das crianças. Optamos pela produção em duplas, com o intuito de estimular o diálogo entre pares, investindo da potência dos diálogos a partir dos distintos pontos de vista. Disponibilizamos folhas de papel de diferentes cores e tamanhos para que pudessem explorar colagens em suas composições sobre o suporte de tamanho A4 (único material disponível naquele contexto) que, mais tarde, poderiam se transformar nas capas de seus cadernos. As crianças foram instigadas fazer uso de lápis coloridos, giz de cera, canetinhas hidrográficas coloridas e colas coloridas. Posteriormente, após finalizadas suas produções 
visuais, plastificamos cada desenho com o intuito de torná-la mais resistente às ações do tempo. A Figura 1, a seguir, apresenta alguns resultados.

Figura 1: Desenho: princesas e príncipes

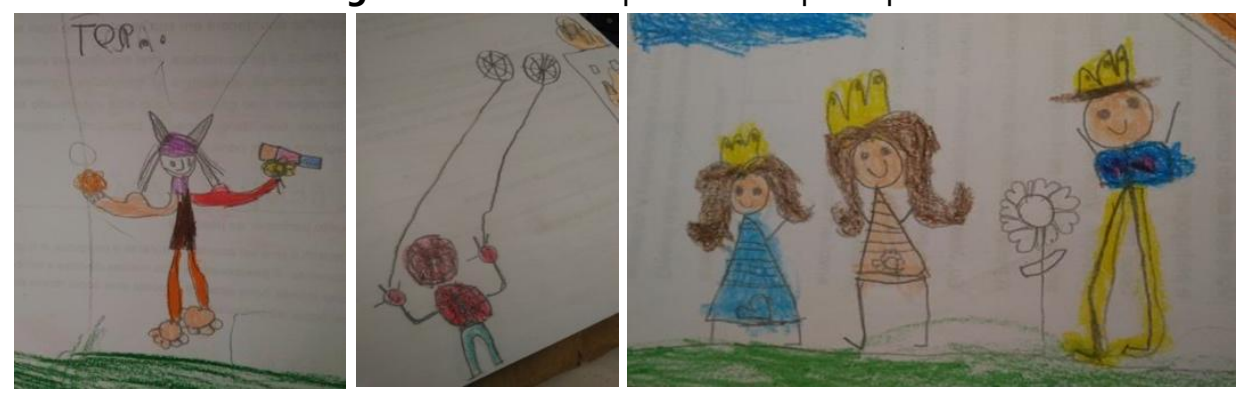

Fonte: arquivo dos autores, 2018.

Em termos de elementos visuais característicos das princesas (vestido longo, cabelos compridos, coroas), a condução da experimentação evidenciou a produção de narrativas visuais pouco diferenciadas daquelas encontradas nas capas dos cadernos e nas mochilas que as crianças apresentaram. Raras foram as representações em que a figura se distanciava desses aspectos quanto a caracterização, adereços, cenários e situações apresentadas. Percebemos que o desafio para os meninos foi maior do que para as meninas, uma vez que não lhes era familiar desenhar princesas. Diante dessa percepção, propusemos que as duplas fossem formadas por uma menina e um menino, no intuito de possibilitar a discussão.

Ao analisar as produções gráficas das crianças, foi possível perceber que desenharam aquilo que thes parecia coerente em resposta às discussões que vínhamos fazendo. Em seguida, reunimos os desenhos em um único suporte, fixado à parede, como forma de compartilhamento coletivo das visões e percepções. Auxiliamos nesse processo de configuração, sempre respeitando seus tempos e provocando alternativas compositivas. Dentre os elementos visuais produzidos, destacamos pequenas casas de diferentes tamanhos e cores, mais simples que castelos, tidos como moradias oficiais das princesas. Também apareceram princesas mulatas e negras, com padrões corporais divergentes, que contemplavam a diversidade presente no contexto que conheciam. Acessórios e brinquedos, como bolas e skates, animais de estimação e situações que vivenciaram, da mesma forma foram elementos recorrentes. Assim, podemos enfatizar que as produções se aproximaram de 
questões contextuais das crianças, ao passo que permitiram adentrar discussões sobre gênero, classe social e etnia.

\section{Perguntando aos super-heróis}

- Super-heróis são bons e ajudam as pessoas. (menino D)

- Eu acho que eles têm algum superpoder. (menina A)

- Eu acho que o Thor não é um super-herói. (menino F)

- É sim, tu não assistiu o filme dele? (menino G)

- Pra mim ele é sim, e ele ajuda muitas pessoas. (menino D)

(Conversas entre crianças. Registros dos autores, 2018)

O diálogo acima, fragmento de uma conversa sobre super-heróis, ocorreu em uma turma do primeiro ano do ensino fundamental, também da unidade social já mencionada. A provocação iniciou por conta dos adesivos com referências visuais aos super-heróis da Marvel, presentes em cadernos que alguns meninos nos mostraram. Neste contexto, percebemos que a troca de figurinhas entre seus pares era uma prática comum - e bastante disputada. $\mathrm{Na}$ época, estavam ocorrendo os jogos da Copa do Mundo, sediados na Rússia, o que também é assunto entre as crianças. Essa movimentação era gerada devido ao álbum da Copa do Mundo com figurinhas dos jogadores de futebol, pois algumas crianças possuíam figurinhas mas não tinham o álbum; outras, tinham o álbum mas não tinham muitas figurinhas; e havia os que não tinham nem um nem outro, mas queriam fazer parte desse universo da troca de figurinhas. Desse modo, nossa proposição artística partiu dessas interlocuções: tomar como referência o tema dos super-heróis com a materialidade dos adesivos e seu modo de compartilhamento.

- Profe, lembra que a senhora falou dos nossos adesivos? (menina A)

- Lembro sim A. Por quê? (pesquisadora)

- É que se a senhora trouxer o material, a gente podia fazer uns adesivos. (menina A)

- Acho que a gente podia fazer um álbum de figurinhas, tipo esse da Copa. (menino D)

- Mas eu não quero desenhar jogadores. (menina J)

- Eu acho difícil também. (menino F)

- Mas, e se a gente fizesse um álbum de super-heróis? (pesquisadora)

- Acho que seria muito legal! (menino F)

- la ser demais! (menino A)

- Mas um pra cada um de nós? (menina L) 
- Eu não poderei vir muitas vezes, então pensei em um álbum da turma, com os super-heróis e super-heroínas que cada uma de vocês criar. O que vocês acham da ideia? (pesquisadora)

- Ah, eu queria um só pra mim. (menina F)

(Conversas entre crianças. Registros dos autores, 2018)

Após algumas conversas, surgiu a ideia da produção de um álbum compartilhado e a criação de figurinhas de super-heróis e super-heroínas, tendo em vista a emergência do tema nas suas brincadeiras e os seus repertórios visuais. Essas produções poderiam partir dos personagens preexistentes, mas ressaltamos que seria interessante que as produções fossem particulares, a partir daquilo que acreditam ser essencial para esse(a) personagem. Buscamos, portanto, fomentar que a criação dos adesivos primasse pelo modo singular de representação, podendo recorrer às figuras híbridas, dotadas de outros superpoderes, e não apenas aquilo que já fazia parte das narrativas que conheciam. Disparamos "e se estes personagens pudessem ter superpoderes diferentes daqueles dos super-heróis da Marvel, que superpoderes seriam estes?"

Ao compartilharem objetos do cotidiano escolar (cadernos, estojos, borrachas, mochilas, canetas), os personagens que mais apareceram foram Homem-Aranha e Batman. Enquanto iam mostrando seus artefatos, questionávamos o que seria necessário para ser um super-herói ou uma super-heroína e percebemos que havia divergência sobre o que atribuíam às princesas - por algumas crianças, vistas como heroínas, por outras, apenas princesas. Seria pelo fato de não visualizarem a representação de super-heroínas nos materiais escolares na mesma intensidade que os materiais destinados aos meninos?

Ao trazermos esta problematização, algumas crianças afirmavam que tanto as princesas como os super-heróis seriam pessoas boas que cuidavam de outras pessoas. Entretanto, outras crianças, principalmente os meninos, não aceitavam essa lógica e ressaltavam a necessidade de um superpoder como característica fundamental para ser considerado super-herói ou uma super-heroína.

Esta proposição gerou como materialidade figurinhas que apresentavam personagens criados pelas crianças. Como materiais gráficos, optamos por canetas hidrográficas, que permitiam a fixação dos desenhos em pedaços de papel adesivo, em diferentes tamanhos e formatos. Desse modo, as crianças teriam que adaptar suas produções de acordo com os suportes diferenciados que foram ofertados (em formatos geométricos variados e/ou 
orgânicos), em dimensões que não ultrapassavam dez centímetros quadrados. Dentre as produções, percebemos o uso frequente de asas nos personagens, roupas coloridas e acessórios, como cintos multiuso, capas e luvas que disparavam luzes e outros efeitos. A Figura 2 faz referência à experiência.

Figura 2: Adesivos produzidos por crianças

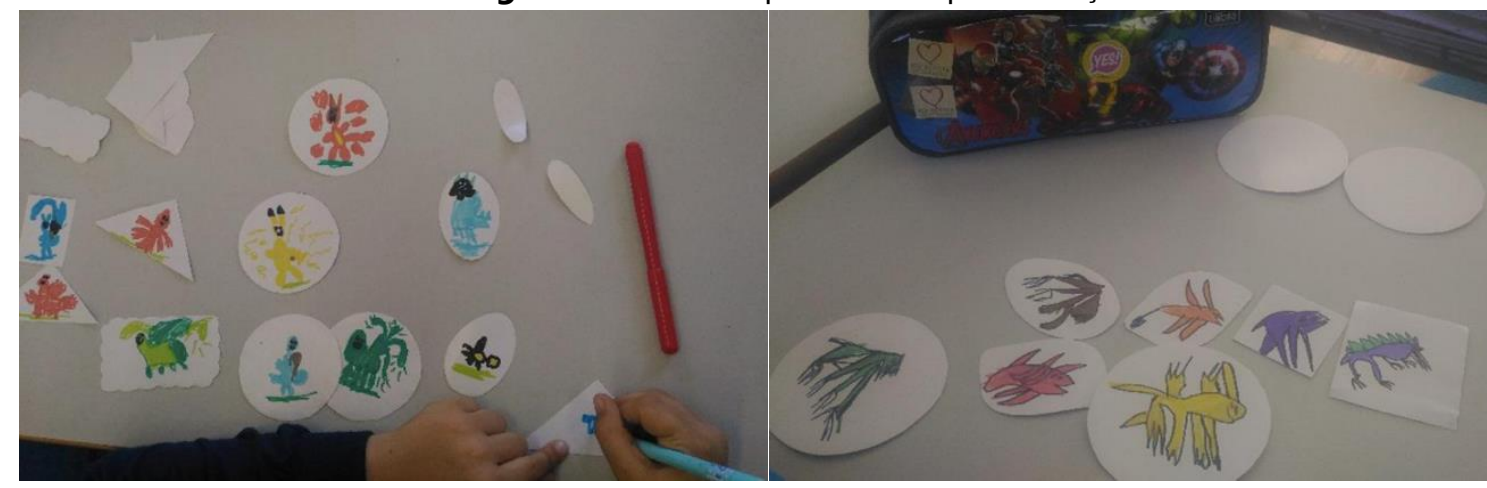

Fonte: arquivo dos autores, 2018.

A discussão seguiu e, como análise desse momento, podemos mencionar que, de modo geral, no entendimento dos meninos da turma, os super-heróis deveriam ter algum superpoder, algo que poderia ser adquirido através de alguma roupa ou acessório. Enquanto isso, as meninas consideravam que boas ações poderiam ser atribuídas aos super-heróis, algo que, segundo elas, seria uma premissa para ocupar esse papel.

Após a produção dos adesivos, as crianças foram convidadas a fixá-los em superfícies diferentes, trocá-los entre seus pares ou guardá-los para momentos posteriores. Ressaltamos outras possibilidades de uso, como criar cartelas de adesivos individuais, ou pequenas figurinhas, entre outras. O álbum fruto da produção coletiva ganhou outro formato: como um painel expositivo, visível a todos e todas, permaneceu por alguns instantes diante de seus olhares atentos e curiosos, permeando apontamentos, risos, surpresas, perguntas, comentários e disputas sobre quais seriam mais poderosos. Brincaram, verbalizaram e dramatizaram os novos poderes criados: gestos corporais, expressões faciais, sonoridades de raios sendo disparados, saltos, simulação de velocidade, lutas, entre outras movimentações que a experiência Ihes possibilitou imaginar. 
Foi possível perceber que muitas das suas referências - a maioria advinda da cinematografia popular - decorriam de narrativas inicialmente destinadas ao público adulto. Muitos dos filmes citados pelas crianças trazem uma faixa etária indicativa mínima de 12 ou 14 anos de idade. Isto é, enredos repletos de cenas de ação, luta corporal, explosões e perseguições que incitam à violência e tendem a estimular brincadeiras baseadas na disputa corporal. Ou seja, brincar de ser super-herói implica em atos de violência e destruição.

Neste sentido, quando pensamos sobre o modo como as crianças acessam referenciais do mundo adulto e como manifestam suas devolutivas, encontramos nas palavras de Corsaro (2002) algumas considerações importantes que nos ajudam a compreender este processo.

(...) a produção da cultura de pares não se fica nem por uma questão de simples imitação nem por uma apropriação direta do mundo adulto. As crianças apropriam-se criativamente da informação do mundo adulto para produzir a sua própria cultura de pares. Tal apropriação é criativa na medida em que tanto expande a cultura de pares (transforma a informação do mundo adulto de acordo com as preocupações do mundo dos pares) como simultaneamente contribui para a reprodução da cultura adulta (CORSARO, 2002, p. 114).

De modo geral, constamos que as produções visuais produzidas pelas crianças não ficaram tão distantes daquilo que elas conheciam e que absorviam dos objetos com os quais nutriam relações afetivas. Super-heróis e princesas que adornavam seus cadernos e povoavam seus imaginários seguiram manifestando sua potência educativa ao se fazerem presentes nas narrativas criadas. Ainda assim, as produções abarcaram olhares singulares, pois apresentaram cores favoritas e algum novo poder que ainda não conhecíamos. Da mesma forma, pudemos verificar a força que esses artefatos exercem sobre as crianças e o que podem enquanto dispositivos pedagógicos, tendo em vista o que pondera Susana Rangel Vieira da Cunha: "a profusão de imagens que acessamos diariamente está presente nas escolas infantis e estas composições formam uma espécie de mestiçagem cultural" (CUNHA, 2014, p. 208).

\section{Olhando para a cidade}

- Vejo um homem segurando uma bola e uma corrente. (Menino A)

- Mas ele é uma estátua! É uma bola de sol. (Menina A)

- Parecido com um anjo! (Menino C)

Olhar de professor, Ponta Grossa, v. 24, p. 1-32, e-117634.077, 2021.

Disponível em <https://revistas2.uepg.br/index.php/olhardeprofessor> 
Pedagogias culturais e proposições pedagógicas: experimentações artísticas com crianças

- Parece uma fada porque tem asas! Uma borboleta! (Menino D)

- É um soldado! (Menido E)

- Eu estou vendo um Deus, com uma corrente segurando os pulsos, e ele está segurando o sol. (Menina A)

(Conversas entre crianças. Registros dos autores, 2019)

O relato que introduz esta nova subseção decorre de uma prática artística desenvolvida em uma escola municipal na cidade de Santa Maria (RS), com crianças de uma turma de primeiro ano do ensino fundamental. Os disparadores para esta experimentação surgiram de diálogos sobre os espaços que as crianças conheciam e percorriam quando não estavam na escola, principalmente a visualização de objetos artísticos em espaços públicos da cidade. Em decorrência deste diálogo, despontaram duas obras facilmente reconhecidas pelas crianças: o monumento O Idealista, do artista Juan Amoretti, e a pintura mural Paisagens da Memória, produzida pelo artista Eduardo Kobra, situada na Biblioteca Municipal. Entre outras imagens de monumentos e obras públicas apresentadas às crianças, essas duas foram aquelas com as quais se percebeu maior reconhecimento.

Logo que a escultura O Idealista foi projetada, muitas das crianças relataram já conhecê-la, compartilhando imediatamente relatos de passagem ou interação com a obra. Da mesma forma, funcionando como ponto de referência para espaços por onde transitavam frequentemente, mostrando que, para além da dimensão estética, a obra funcionava também como dispositivo de localização ou de memória de alguma vivência:

- Sora, eu já fui neste lugar, foi lá onde o meu pai comprou a cestinha da minha bicicleta. (Menina G)

- Isto é lá no fim do centro! Eu já subi aqui e ali, mostrando na imagem. (Menino B)

- É onde o meu pai passa para ir para o trabalho. (Menino A)

- Sempre que vou para minha vó Marta eu passo por ali. (Menino F)

(Conversas entre crianças. Registros dos autores, 2019)

Movimentados pelo desejo de fomentar, nas crianças, reflexões sobre os espaços coletivos por onde transitamos e a percepção visual dos objetos - assim como arquitetura local, vias públicas e demais elementos que constituem o centro urbano e as periferias da cidade -, selecionamos e compartilhamos imagens fotográficas de vários espaços públicos locais. O intuito inicial era perceber como se dava a relação entre espaço e produção artística 
tridimensional. Ou seja, compreender características da produção escultórica em relação ao entorno ao qual ela estaria vinculada, estabelecendo relações entre espaços cheios e vazios, texturas e formas, proporção e profundidade, noções de verticalidade e horizontalidade.

Para além de uma análise formal, foram estimulados processos de interpretação. Instigados a falar sobre a escultura, os que já conheciam relataram diversas perspectivas e explicações e até mesmo respostas que povoam seus imaginários infantis, tais como a relação com seres extraterrenos, divindades ou personagens midiáticos. Aproveitando o engajamento curioso, questionamos se havia, em seu cotidiano, algo que se assemelhava com a estátua ou que tivesse alguma relação/significado para eles/as.

- Eu conheço o Deus da guerra, no primeiro capítulo, com duas correntes nos pulsos. (Menino B)

- Eu acho que ele está segurando o sol, para os anjos deixarem a vida melhor. (Menino F)

(Conversas entre crianças. Registros dos autores, 2019)

A cada diálogo e narrativa compartilhada, as crianças traziam representações acerca das suas vivências, produzidas pelos distintos contextos próprios de sua idade, em que o universo da fantasia é bastante recorrente. Por esta via, procuramos perceber quais repertórios visuais sobre o tema as crianças traziam consigo, o que nos possibilitaria estabelecer alguns vínculos entre referenciais locais já familiares e outras/novas conexões com obras e artistas cujas produções artísticas perpassam Arte Pública, Intervenções Artísticas ou Esculturas Contemporâneas.

Partindo dessa consideração, notamos que o repertório cultural e imagético já conhecido das crianças favorece a prática de estabelecer relações entre obras de artistas de diferentes períodos da História da Arte, como obras de Arte Contemporâneas e até mesmo produções midiáticas atuais. Assim, é possível trabalhar a ampliação do repertório artístico das crianças e criar uma rede de conexões com aquilo que elas já conhecem, o que potencializa outros desdobramentos. Em suas interações sociais junto à família, à escola, aos lugares que percorrem e às imagens que consomem diariamente, as crianças vão construindo seus repertórios visuais; alguns intencionais, outros a partir de influências midiáticas ou da própria família. 
Quando apresentadas à imagem de O Idealista, várias crianças reproduziram o movimento que a escultura permitia, numa gestualidade própria e espontânea, através do balanço dos corpos, do equilíbrio e da posição, imaginando-se a escultura. Posteriormente, iniciaram suas representações gráficas através do desenho, fazendo uso de materiais convencionais, como papel sulfite, lápis de cor, canetinhas hidrográficas e giz de cera. Exploraram seus imaginários através de combinações de formas coloridas simulando movimentos semelhantes ao da escultura. Além do material de desenho, foi disponibilizada massa de modelar colorida, material em que as crianças seguiram fazendo referência à escultura, explorando a densidade e solucionando problemas, como a verticalidade e a sustentação da figura. A Figura 3 apresenta alguns resultados:

Figura 3: Produções infantis a partir do monumento O Idealista
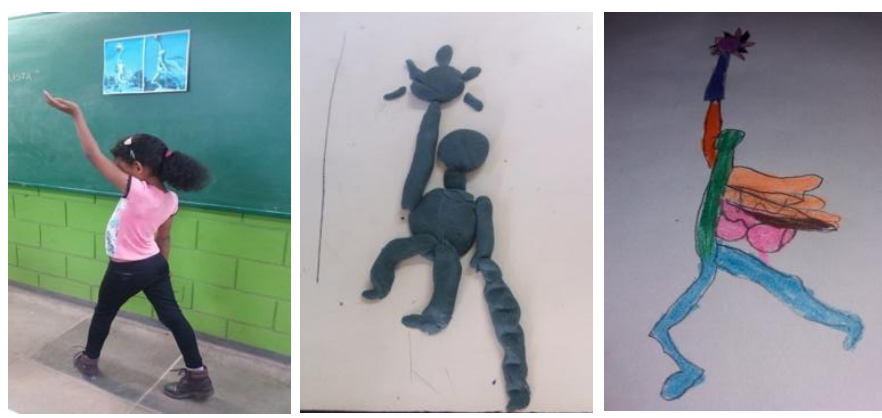

Fonte: arquivo dos autores, 2019.

Em uma segunda parte, nossa intervenção se deu partir do compartilhamento de uma imagem fotográfica do mural de Eduardo Kobra localizado na parte externa da Biblioteca Pública. Apesar de não conhecerem muito bem a imagem apresentada, as crianças sentiram a necessidade de participar, acolhendo-a em suas narrativas, inventando seu contexto. A gigantesca pintura produzida em uma paleta de tons acinzentados reproduz uma fotografia panorâmica da cidade de Santa Maria da década de 1950. O painel produzido em 2010, em comemoração ao $152^{\circ}$ aniversário da cidade, inicialmente lhes provocou indiferença, apesar de ser uma imagem que apresenta, em síntese, uma avenida atravessada por veículos, transeuntes, árvores, prédios e elementos típicos de uma cidade de pequeno porte no início dos anos 50. Talvez, a indiferença se deu pelo fato da ausência da corou por se tratar de uma 
imagem não familiar. Entretanto, quando provocadas a relatar o que viam na imagem, dispararam:

\author{
- Eu vejo postes, escadas, carros, e duas pilastras. (menino B) \\ - É uma cidade, árvore, bancos e uma casa grande. (menino A) \\ -Eu ainda não aprendi sobre as ruas, mas acho que é perto de uma pracinha \\ que eu já fui. (menina $A$ ) \\ (Conversas entre crianças. Registros dos autores, 2019)
}

Conforme Taschetto (2014, p. 37), a Arte Pública "é constituída por um conjunto de significações que interagem entre si, em um processo de pertencimento do e no espaço/tempo ao interagirem com o público e o conjunto da cidade". Tomados por esta concepção, buscamos instigar as crianças a identificar a localização do painel por meio de indagações, incentivando-as a imaginarem situações para a imagem, narrativas que pudessem dar conta da cena que estava sendo representada. Ao se sentirem autorizadas a inventar estórias para a imagem projetada, percebemos que a dinâmica de devolver às crianças o poder de interpretação segue sendo um potente recurso para fomentar seu protagonismo. Acreditamos que, implicitamente, estamos dizendo que não há regras para interpretar uma obra ou uma imagem, mas o jeito peculiar de cada um(a).Para estas práticas, novamente foram disponibilizados materiais convencionais: canetões coloridos, papéis para colagem, giz de cera e lápis de cor. De posse desses materiais, as crianças produziram quatro painéis colaborativos, híbridos em suas narrativas visuais e representações. A Figura 4 apresenta alguns resultados desta proposição:

Figura 4: Produções infantis a partir do mural de Eduardo Kobra

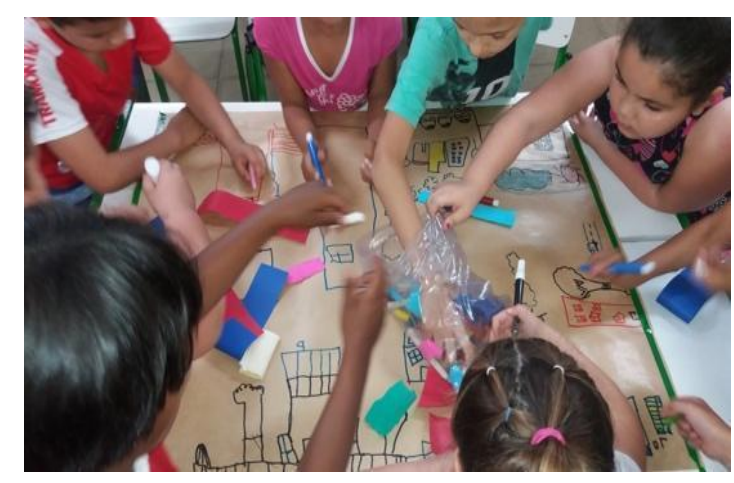

Fonte: arquivo dos autores, 2019. 
Pedagogias culturais e proposições pedagógicas: experimentações artísticas com crianças

A partir dessas experiências, acreditamos na potência pedagógica da problematização das imagens ao colocá-las em relação, sobretudo ao estabelecer conexões entre as experiências cotidianas, repertórios visuais que as crianças trazem e compartilham. Da mesma maneira, o universo fantástico que estimula a criação de enredos possíveis para cenas ou situações, igualmente favorecem o protagonismo, pois cria um espaço de exercício criativo e de experimentação isenta de julgamento.

Obras e monumentos presentes em espaços urbanos frequentados por nós e pelas crianças puderam se configurar em dispositivos pedagógicos para que as crianças aprendessem sobre nossas referências culturais envolvendo outros campos disciplinares, como a geografia e a história. Ao situarmos as duas obras escolhidas como mote para as experimentações artísticas, falamos dos nossos contextos, entrelaçamos trajetos ao localizar cada uma das referências no mapa da cidade, mapeando linhas imaginárias entre nós e os outros.

\section{Reconfigurando medos}

- Profe, quero ir lá não. Tenho medo dos palhaços. (Menino B) (Conversas entre crianças. Registros dos autores, 2018)

A última experimentação artística que compartilhamos neste texto foi realizada no ano de 2019 junto ao projeto de voluntariado Turma do Chiquinho, na EMEI Sinos de Belém, em Santa Maria (RS). Consiste em um trabalho realizado com crianças da educação infantil, com idades entre 4 e 5 anos. As práticas do projeto são organizadas a partir de aspectos percebidos, pelos voluntários e pela professora regente da turma, como dispositivo pedagógico.

Entre variadas proposições, destacamos uma experiência disparada a partir do relato de uma criança acerca do medo de palhaços - na ocasião, havia um circo nas redondezas da escola, o que estaria the causando insegurança. O relato surgiu espontaneamente quando as crianças foram reunidas e solicitadas a comentar sobre o espaço em que estavam inseridas e sobre o que poderíamos construir em conjunto. Ao escutarem o relato, as demais crianças igualmente quiseram comentar sobre seus medos. Entre tantos medos, os medos do escuro, de bruxas, de monstros, de fantasmas, do bicho-papão, do lobisomem e de outros seres fantásticos predominaram as manifestações. Ouvimos também relatos sobre medos que 
acreditamos que nenhuma criança deveria sentir: medo do abandono, de sofrer agressões dos pais sob efeito do álcool ou outras drogas. Devolutivas que nos impactaram e, ao mesmo tempo, nos provocaram como tema a ser abordado na proposição. Em outro momento, contatamos a professora regente e a equipe diretiva para que a escola tivesse ciência dos relatos e, dentro de suas possibilidades, tomar medidas cabíveis, tanto do acolhimento das narrativas, como possíveis acompanhamentos profissionais às famílias das crianças.

Para iniciarmos, partilhamos a leitura de "Quem tem medo de quê?", da autora Ruth Rocha (2012), como forma de introduzir a temática. De modo descontraído, contamos a história e comentamos sobre nossos medos. Julgamos conveniente falar que adultos também têm medo e que existem formas de lidar com eles, que pode ser compartilhando com outras pessoas, com ajuda profissional ou outras alternativas voltadas ao lúdico. Desse modo, tivemos momentos de partilha em uma roda de conversa e, sempre que possível, realizávamos dramatizações ou demonstrações sonoras que nossos medos produziam, como uma forma de lançar convites à fantasia e à criação.

Após esses compartilhamentos, problematizamos qual elemento poderia representar simbolicamente nossos enfrentamentos diante dos nossos medos. Após muitas ideias, surgiu a proposta de criação de uma capa de proteção contra medos. Com base nos repertórios visuais dos super-heróis apresentados pelo cinema, em que as capas integram seus trajes e os diferenciam dos demais humanos, percebemos que tínhamos uma oportunidade, inclusive, de relacionar a atividade com artistas como Hélio Oiticica (a partir dos Parangolés) e Rivane Neuenschwander. Nesse sentido, a obra O nome do medo, da artista plástica mineira Neuenschwander, contribuiu para pensarmos na experimentação artística, na ludicidade e no simbolismo que envolve essa capa de proteção como possibilidade de ampliação de repertório artístico para as crianças.

Diálogos acerca dos medos continuaram e também sobre os materiais que usariam (desenhos, cores, elementos decorativos e espaços em que usariam as capas). Para a confecção das capas, cada criança decidiu o tamanho, o formato, a cor e quais elementos dentre aqueles disponíveis integrariam suas produções (lantejoulas, tecidos, cola colorida, cola glitter, pequenos desenhos, fitas, laços, etc.). Na Figura 5, imagens das capas produzidas em TNT. 
Figura 5: Capas de TNT produzidas pelas crianças.
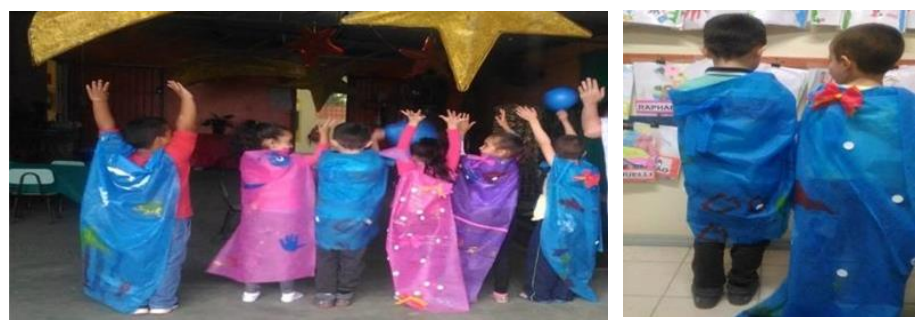

Fonte: arquivo dos autores, 2018.

Auxiliamos no manuseio de alguns materiais, como tesouras e cola quente, e também no estímulo à exploração de materiais alternativos. Ao término, as crianças vestiram suas capas e brincaram pelo pátio, simbolicamente protegidas de seus medos e orgulhosas de suas produções. Dançaram, cantaram e ensaiaram duelos embalados por muitos sorrisos e satisfação em poderem materializar, por meio da poética inventiva das artes, reflexos de suas singularidades.

\section{Notas provisórias sobre alguns achados}

Em todo caso, parece-nos fundamental pensar que a educação das artes visuais não pode se restringir a refletir a partir da pedagogia das imagens, em particular em termos de suas influências na conformação das visualidades das infâncias, das adolescências e dos jovens, suas representações e seus significados. Crianças, adolescentes e jovens estão em permanentes diálogos, trocas e trânsitos de múltiplas negociações com as imagens (MIRANDA, 2014, p. 294).

Ao compartilhar nossas experiências de aprender com as crianças, atravessadas por diferentes materialidades e experimentações artísticas, seguimos reiterando a importância da escuta atenta às suas percepções de mundo trazidas para o espaço coletivo como fonte de inspiração para formularmos conexões com os contextos que habitam. Partindo de seus repertórios visuais enredados pelos afetos, foi possível potencializar, para além do fazer artístico, a prática de estabelecer relações entre si e o universo, sem lhes negar o caráter sedutor das imagens que selecionam e os acompanham em suas andanças.

Mapear interesses e afetos, conectar e estabelecer relações entre narrativas, recortes, imagens distintas se configuraram importantes movimentos às nossas práticas docentes. Ao final desta jornada (a escrita de um artigo que busca dar conta das experiências vividas), 
voltamos nosso olhar às nossas formas de perceber e significar práticas pedagógicas com as crianças. As possibilidades são infinitas, e não há receitas de um como fazer. Do mesmo modo, não estamos lidando com perspectivas que permeiam o certo ou errado, uma vez que optamos por vias de experimentação, de escuta e acolhimento. Escolhemos por tornar potentes os imaginários e as narrativas visuais impulsionadas pelos variados dispositivos que movimentaram (e seguem movimentando) nossos pensamentos e ações enquanto sujeitos em devir.

Ao mergulhar no caminho percorrido ao longo dessas vivências, percebemos que as crianças do tempo presente diferem completamente das referências imagéticas das infâncias que o modernismo segue nos brindando. Lidamos com infâncias atravessadas pela intolerância do mundo adulto, que têm medo de serem abandonadas ou agredidas dentro de suas casas, embebidas pela falta de tempo do mundo do trabalho, dilaceradas pelas relações familiares que, muitas vezes, delegam aos espaços educativos a função de ensinar seus filhos e filhas a serem cidadãos éticos, morais e corretos, além do desenvolvimento das suas inteligências disciplinares. Da mesma forma, são infâncias que se desenvolvem frente aos dispositivos móveis, consumindo, desde muito cedo, produtos culturais da indústria do entretenimento. De super-heróis a princesas, os imaginários coletivos seguem impondo padrões hegemônicos às brincadeiras, sobretudo no que tange às suas formas de se relacionar como meninos ou meninas. Se, por um lado, vivemos a era do acesso à informação a partir de um toque dos nossos dedos, o conhecimento reflexivo e crítico segue atravessado por interesses hegemônicos que almejam sua manutenção - basta acompanhar todo o abanico de produtos destinados ao consumo infantil baseado em perspectivas binárias e sexistas, começando pelo uso das cores e brinquedos populares.

A partir dos repertórios visuais que integram nossos cotidianos, é evidente que necessitamos considerar aspectos que envolvem a construção dos desejos e que estão impregnados de ideologias que se inscrevem nos artefatos visuais públicos. A sala de aula recebe e abriga, constantemente, infinitas referências à moda, aos variados programas de TV em canal aberto ou privado; ainda, há outras referências advindas das redes sociais, da publicidade e, sobretudo, do cinema, que é produzido com vistas às infâncias contemporâneas 
por meio do consumo de inúmeros objetos afetivos (camisetas, acessórios, brinquedos, materiais escolares, etc.).

Ao fazermos uso de metodologias dialógicas - em que as inquietações de todos e todas não seguem hierarquias, mas se potencializam pela prática de fazer perguntas - e explorarmos e amplificarmos as distintas vozes, estaremos fomentando espaços de interação entre estudantes e docentes, fortalecendo o caráter pedagógico baseado na colaboração e no compartilhamento. No âmbito das políticas de representação, isso favorece a criticidade diante das imagens que circunscrevem formas de ver e ser visto pelas constantes narrativas que tendem a reforçar visões (e versões) estereotipadas de gênero e classe social. Nesse sentido, a descentralização da atuação do professor em sala de aula como aquele que decide os percursos que cada sujeito deve seguir abre, ao espaço educativo, distintas formas de ensinar e aprender, onde nada é fixo, todos podem encontrar o seu lugar e todas as perguntas podem ser incluídas.

Assim como as perguntas fortuitas produzidas pelo criador das pinturas Mona Lisa e Última Ceia, as perguntas formuladas pelas nossas crianças podem abrir espaços de interação e generosidade, de fomento à inventividade e ao pensamento singular, que, em síntese, é capaz de transformar o ordinário em extraordinário. Da mesma forma, subverte os discursos impostos, de modo a indagar as estruturas hegemônicas que continuam a definir condutas e formas de ser e atuar num mundo cada vez mais incerto, em que os medos das crianças ultrapassam os imaginários da fantasia e se tornam cada vez mais reais: na violência de gênero, no abuso infantil, no bullying, no não ter o que comer, entre tantos outros medos que, lamentavelmente, atravessam as duras realidades.

\section{Referências}

CORSARO, W. A reprodução interpretativa e o brincar de "faz de conta" das crianças.

Educação, Sociedade e Culturas, Portugal, n. 17, p. 113-134, 2002.

COSTA, M. V. Imagens do consumismo na escola - a produtividade da cultura visual. Instrumento: R. Est. Pesq. Educ., Juiz de Fora, v. 14, n. 2, jul./dez. 2012. Disponível em: https://periodicos.ufjf.br/index.php/revistainstrumento/article/view/18774 Acesso em: 15 jun. 2021. 
CUNHA, S. R. V. da. As infâncias nas tramas da cultura visual. In: MARTINS, R.; TOURINHO, I. (Orgs.). Cultura visual e infância: quando as imagens invadem a escola. 1. ed. Santa Maria: UFSM, 2010.

CUNHA, S. R. V. da. A importância das artes na infância. In: CUNHA, S. R. V. da. (Org.). As artes no universo infantil. Porto Alegre: Mediação, 2014a.

CUNHA, S. R. V. da. Imagens na educação infantil como pedagogias culturais. In: MARTINS, R.; TOURINHO, I. (Orgs.). Pedagogias culturais. Santa Maria: UFSM, 2014 b.

CUNHA, S. R. V. da. A arte do nosso tempo para as crianças de hoje. In: CUNHA, S. R. V. da.; CARVALHO, R. S. de. (Org.). Arte contemporânea e educação infantil. Porto Alegre: Mediação. 2017.

DUNCUM, P. Por que a arte-educação precisa mudar e o que podemos fazer. In: MARTINS, R.; TOURINHO, I. (Orgs.). Educação da cultura visual: conceitos e contextos. Santa Maria: UFSM, 2011.

GIROUX, H. Cine y entretenimiento: elementos para una crítica política del filme. Barcelona: Paidós, 2003.

GRAUE, E.; WALSH, D. Investigação etnográfica com crianças: teorias, métodos e ética. Lisboa: Fundação CalousteGulbenkian, 2003.

HERNÁNDEZ, F. Catadores da cultura visual: proposta para uma nova narrativa educacional. Porto Alegre: Mediação, 2007.

HERNÁNDEZ, F. Para Erina ninguém dia nada... e nós não podemos fazer o que queremos: a educação da cultura visual na educação infantil. In: MARTINS, R.; TOURINHO, I. (Orgs.).

Cultura visual e infância: quando as imagens invadem a escola. Santa Maria: UFSM, 2010.

HERNÁNDEZ, F. Pedagogias culturais: o processo de (se) constituir em um campo que vincula conhecimento, indagação e ativismo. In: MARTINS, R.; TOURINHO, I. (Orgs.) Pedagogias culturais. Santa Maria: UFSM, 2014.

ISAACSON, W. Leonardo da Vinci. Rio de Janeiro: Intrínseca, 2017.

KINCHELOE, J.; BERRY, K. Pesquisa em educação: conceituando a bricolagem. Porto Alegre: Artmed, 2007.

MARTINS, R.; TOURINHO, I. Circunstâncias e ingerências da cultura visual. In: MARTINS, R.; TOURINHO, I. (Orgs.). Educação da cultura visual: conceitos e contextos. Santa Maria: UFSM, 2011.

MARTINS, R.; TOURINHO, I. Pedagogias culturais (Orgs.). Santa Maria: UFSM, 2014. 
MIRANDA, F. Pedagogia das imagens: de artes visuais e shopping centers. In: MARTINS, R.; TOURINHO, I. (Orgs.). Pedagogias culturais. Santa Maria: UFSM, 2014.

MOMO, M. As crianças de hoje não são mais como antigamente! Implicações culturais do mundo contemporâneo para os modos de ser criança e de viver a infância. Textura, Canoas, n. 32, p. 7-21, set./dez. 2014. Disponível em:

http://www.periodicos.ulbra.br/index.php/txra/article/view/1243 Acesso em: 15 jun. 2021.

NUNES, A. Sobre a pesquisa enquanto bricolagem, reflexões sobre o pesquisador como bricoleur. Revista Digital do LAV, Santa Maria, v. 7, n. 2, p. 30-41, maio/ago. 2014.

ROCHA, R. Quem tem medo de quê? Rio de Janeiro: Salamandra, 2012.

SILVA, T. T. da. Documentos de identidade: uma introdução às teorias do currículo. Belo Horizonte: Autêntica, 1999.

TASCHETTO, M. U. O mural de Eduardo Kobra em Santa Maria: uma relação com a arte pública. 2014. Dissertação (Mestrado em Artes Visuais) - Universidade Federal de Santa Maria, Santa Maria, 2014. Disponível em: https://repositorio.ufsm.br/handle/1/5227. Acesso em: 15 jun. 2021.

TAVIN, K. Contextualizando visualidades no cotidiano: problemas e possibilidades do ensino da cultura visual. In: MARTINS, R.; TOURINHO, I. (Orgs.). Educação da cultura visual: narrativas de ensino e pesquisa. Santa Maria: Ed. UFSM, 2009.

TAVIN, K.; ANDERSON, D. A cultura visual nas aulas de arte no ensino fundamental: uma desconstrução da Disney. In: MARTINS, R.; TOURINHO, I. (Orgs.). Cultura Visual e Infância: quando as imagens invadem a escola. Santa Maria: UFSM, 2010.

VALLE, L. D. Aprendendo a ser docente através dos filmes: possíveis trânsitos entre cinema e educação. In: MARTINS, R.; TOURINHO, I. (Orgs.). Pedagogias culturais. Santa Maria: UFSM, 2014.

VALLE, L. D. Cultura visual e educação: cartografias afetivas e compreensão crítica das imagens. Revista Cadernos de Comunicação, Santa Maria, v. 24, n. 1, p. 9-20, jan./abr. 2020.

Recebido em: 15 de março de 2021.

Versão corrigida recebida em: 26 de junho de 2021.

Aceito em: 26 de junho de 2021.

Publicado online em: 21 de agosto de 2021.

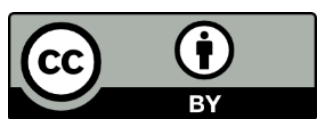

Olhar de professor, Ponta Grossa, v. 24, p. 1-32, e-17634.077, 2021.

Disponível em <https://revistas2.uepg.br/index.php/olhardeprofessor> 